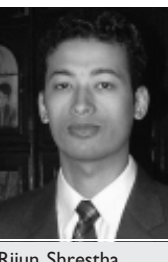

Rijun Shresth

Doctoral Candidate, Centre for Built

frastructure Research, Faculty of

Engineering and Information Technology,

University of Technology Sydney, Australia
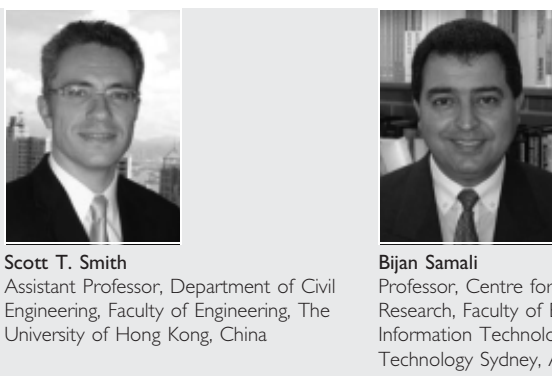

Bijan Samali

Professor, Centre for Built Infrastructure

Research, Faculty of Engineering and

Information Technology, University of

Technology Sydney, Australia

\title{
Strengthening RC beam-column connections with FRP strips
}

R. Shrestha BE, S. T. Smith PhD, MIEAust, CPEng and B. Samali DSc, MIEAust, MASCE

Reinforced concrete connections, designed prior to the implementation of earthquake design standards, may be vulnerable to shear failure during a seismic attack. Addition of externally bonded fibre-reinforced polymer (FRP) composites can enhance not just the shear capacity but the deformation and energy absorption capacity of the connection. The majority of research studies to date have opted for complete or nearcomplete coverage of the joint region with FRP and have subjected the test specimens to cyclic (push-pull) loading. Such strengthening schemes and method of loading make it quite difficult to accurately monitor and hence understand the behaviour of the FRP and the concrete beneath. This paper presents results of a series of tests on the strengthening of shear deficient connections with FRP strips subjected to either cyclic or monotonic loading with the primary motivation being accurate description of the behaviour of the FRP. The tests also enable the failure modes to be more accurately reported and classified especially due to the use of monotonic loading. An analytical model is finally presented which accurately describes the mechanics of the FRP strengthening with the model predictions correlating reasonably well with the test data.

\section{NOTATION}

$A_{\text {frp }, i} \quad$ cross-sectional area of FRP strip crossing the joint

$b \quad$ joint dimension perpendicular to the direction of FRP or joint width

$b_{\mathrm{c}} \quad$ concrete width

$b_{\mathrm{p}} \quad$ FRP width

$D_{\text {frp }} \quad$ distribution factor

$d \quad$ column depth

$E_{\mathrm{p}} \quad$ modulus of elasticity of FRP

$f_{\mathrm{c}}^{\prime} \quad$ compressive cylinder strength of concrete

$\mathrm{f}_{\text {frp,deb }, i}$ stress in FRP at debonding

$h \quad$ beam depth

$L_{\mathrm{b}} \quad$ distance of beam tip load to the column centreline

$L_{\mathrm{c}} \quad$ length of column between points of contra-flexure

$M_{\mathrm{j}, \text { centre }}$ moment at joint centre

$n \quad$ number of FRP strips

$P_{\mathrm{b}} \quad$ beam tip load

$T_{\mathrm{b}} \quad$ total tensile force in beam section

$T_{\mathrm{b}, \text { frp }} \quad$ tensile force in beam FRP

$T_{\mathrm{b}, \mathrm{s}} \quad$ tensile force in beam internal steel

$t_{\mathrm{p}} \quad$ FRP thickness
$V_{\mathrm{c}} \quad$ column shear force

$V_{\mathrm{jh}} \quad$ horizontal joint shear force

$V_{\mathrm{jv}} \quad$ vertical joint shear force

$\alpha \quad$ empirical factor

$\beta \quad$ angle between FRP strip to column axis

$\beta_{1} \quad$ FRP length factor

$\beta_{\mathrm{p}} \quad$ FRP width factor

$\varepsilon_{\mathrm{cf}} \quad$ strain in extreme concrete compression fibre

$\theta \quad$ angle between critical diagonal crack to column axis

$\sigma_{\text {axial }} \quad$ column axial stress

$\sigma_{\mathrm{p}} \quad$ bond strength of FRP-to-concrete joint

$v_{\text {frp }}$,model calculated FRP contribution to joint shear strength

$v_{\text {frp,test }} \quad$ tested FRP contribution to joint shear strength

$v_{\mathrm{j}} \quad$ joint stress

$v_{\mathrm{jh}} \quad$ horizontal joint shear stress

$v_{\mathrm{jv}} \quad$ vertical joint shear stress

$\rho_{\text {frp }} \quad$ FRP reinforcement ratio

\section{INTRODUCTION}

Reinforced concrete (RC) structures were typically designed for gravity loads only prior to the implementation of earthquake standards. The region where the beam frames into the column in such structures (i.e. joint region) required the placement of little to no shear reinforcement (i.e. transverse reinforcement) (Figure 1). The high shear forces induced in the joint region due to seismic attack can lead to diagonal cracking in the joint region (Figure 2), which may ultimately lead to shear failure.

Reinforcement details for both exterior (i.e. one beam framing into a column) and interior (i.e. two beams framing into a column) shear deficient connections are shown in Figure 1, although only exterior connections are considered in this study.

It has been demonstrated that externally bonded fibrereinforced polymer (FRP) composites can effectively strengthen $\mathrm{RC}$ connections (i.e. connections referring to the joint region including the beam/s and column/s framing into the joint). Both exterior and interior connections have been tested with externally bonded FRP to enhance the connection shear capacity ${ }^{1-4}$ or to enhance the anchorage capacity of poorly anchored longitudinal beam reinforcement. ${ }^{5,6}$ In addition, FRP has been used to enhance both the shear strength of the connection and anchorage of the beam reinforcement ${ }^{7,8}$ and also to relocate the formation of plastic hinging further along the beam away from the joint. ${ }^{9}$ The majority of research conducted on FRP-strengthened connections has been experimental with a comprehensive review of experimental 


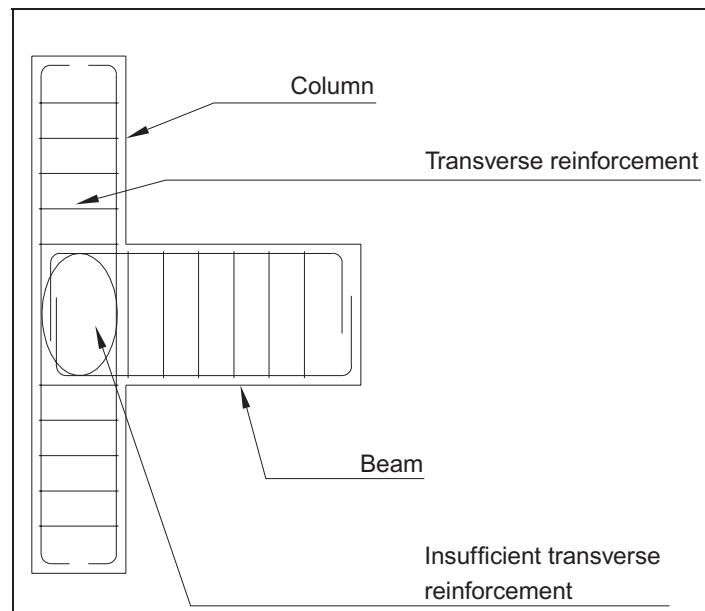

(a)

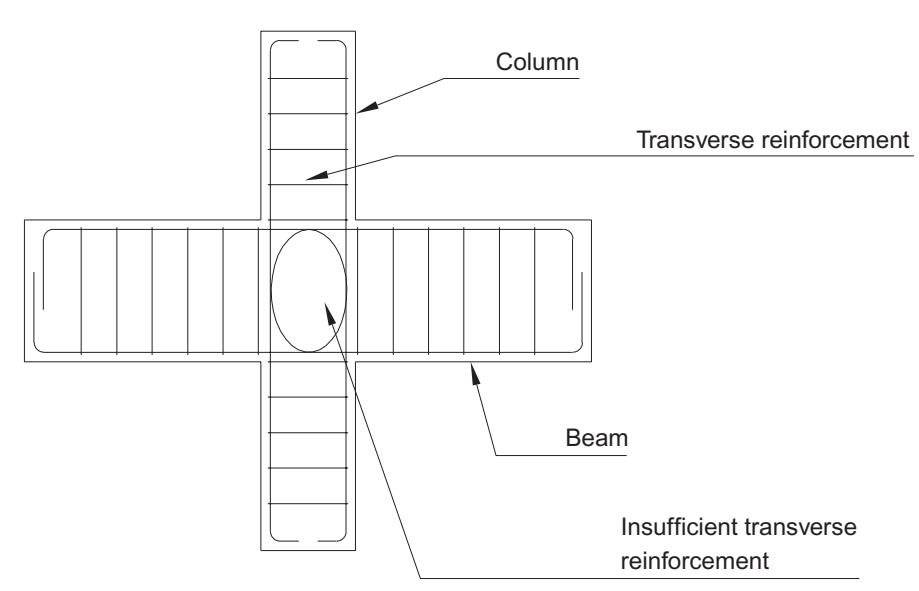

(b)

Figure I. Connections deficient in shear capacity: (a) exterior connection; (b) interior connection (dimensions in mm)

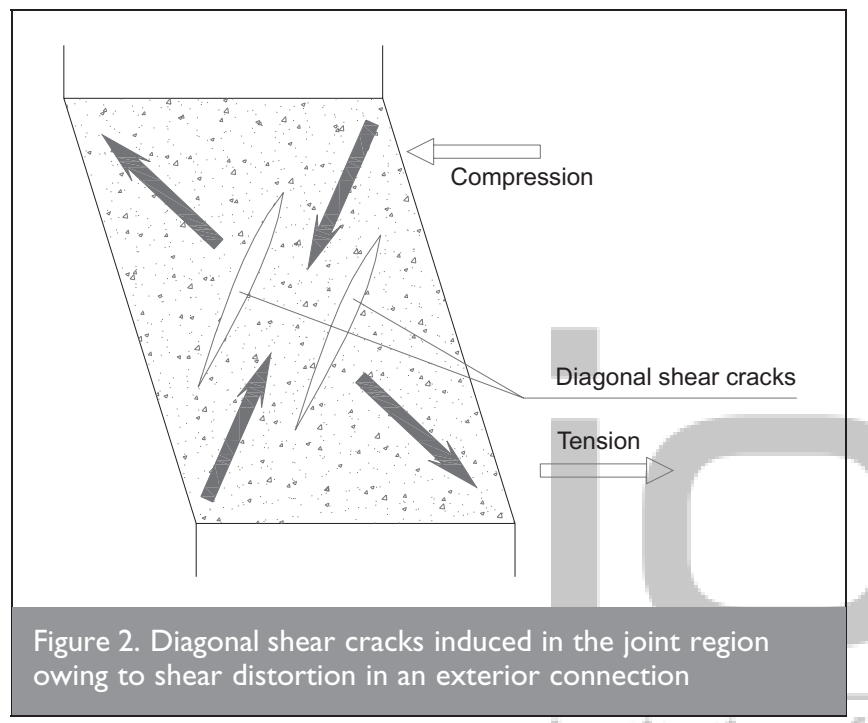

research to date in addition to an evaluation of the effectiveness of the strengthening schemes given in Smith and Shrestha. ${ }^{10}$ A review of non-FRP strengthening solutions, as well as some FRP ones, is given in Engindeniz et al. ${ }^{11}$

The majority of previous experimental studies have reported the behaviour of FRP-strengthened connections subjected to cyclic loading of increasing push-pull amplitude until failure. The hysteresis responses of the connection were typically plotted and the strength, ductility and energy absorption capacity shown to increase. Such tests were therefore aimed at observing the overall behaviour of the connections with limited information offered on the behaviour of the FRP alone (e.g. strain distribution along the FRP strengthening) or detailed reporting of the failure mode.

The primary objectives of the tests reported herein are to observe the behaviour of the FRP strengthening and accurately report the failure mode of the strengthened connection in exterior RC connections. Simple strengthening schemes using carbon FRP strips were tested which enabled easy monitoring of the FRP and adjacent concrete in the joint region. Linear variable displacement transducers (LVDTs) and electric strain gauges have been extensively utilised. Connections were tested either under increasing monotonic or cyclic load where monotonic loading made it easy to observe the overall behaviour of the connection and the behaviour of the FRP strengthening. An analytical model is also presented, which simply but accurately models the mechanics of the strengthened joint and correlates reasonably well with the test data.

\section{EXPERIMENTAL DETAILS}

\section{I. Description of test specimens}

Two sets of exterior connections were tested. The first set was subjected to monotonic load and consisted of three connections (i.e. one control and two strengthened with FRP) while the second set was conducted under cyclic loading and consisted of two connections (i.e. one control and one strengthened with FRP). A summary of key parameters of all tested connections is presented in Table 1.

All the connections were designed with no transverse reinforcement in the joint region as illustrated in Figure 1(a). Geometric properties and reinforcement details of the connections are shown in Figure 3. The connections were designed to fail in the joint region first for both the control specimens as well as the FRP-strengthened specimens so that failure of the FRP-strengthened region could be captured. It should be noted that the commonly recognised philosophy for 
designing seismically resistant RC frames is the strong column-weak beam principle; however, it was not the intention of this study to simulate such behaviour. The relationships between the strength and stiffness of the column to that of the beam were realistically assumed in the design. Of course in reality the joint region will not fail but the beam should fail first by plastic hinging.

Two different FRP strengthening techniques were used in this study, both using carbon FRP (CFRP but herein referred to as FRP) strips formed from carbon fibre sheets in a wet lay-up process. The column strip scheme (Figure 4(a)) had two $50 \mathrm{~mm}$ wide strips applied on either side of the joint face which extended into the column. Column wraps were provided on both ends of the strips to provide anchorage against complete strip debonding. Two layers of fibre sheet were used to form the FRP in both the strips and in the column wraps. The beam strip scheme, shown in Figure 4(b), consisted of three FRP strips oriented parallel to the longitudinal axis of the beam. Each strip consisted of two layers of FRP applied around the joint region, which also extended into the beam in a U-shape. The ends of the strips were anchored using beam wrapping formed from two layers of fibre sheet. Both the beam strip and column strip strengthening schemes had a constant FRP reinforcement ratio $\rho_{\text {frp }}$ of $0.052 \%$, (where $\rho_{\text {frp }}$ is the cross-sectional area of the FRP divided by the joint dimension perpendicular to the direction of FRP and the depth of the section).

FRP strips were chosen as opposed to sheets in order to monitor the progression of cracking in the joint region more easily in addition to detecting the occurrence of debonding of the FRP. Also, the beam and column wraps provided anchorage to the FRP strips against global debonding, which in turn made the strengthening schemes quite unique in nature. In order to ensure a good bond between the concrete and FRP, the surface of the concrete was scaled back using a needle gun and all dust particles were removed by flushing with a compressed airgun. Concrete corners were rounded to a radius of $25 \mathrm{~mm}$ (ACI440-2R-08 ${ }^{12}$ specifies a minimum corner rounding radius of $13 \mathrm{~mm}$ ).

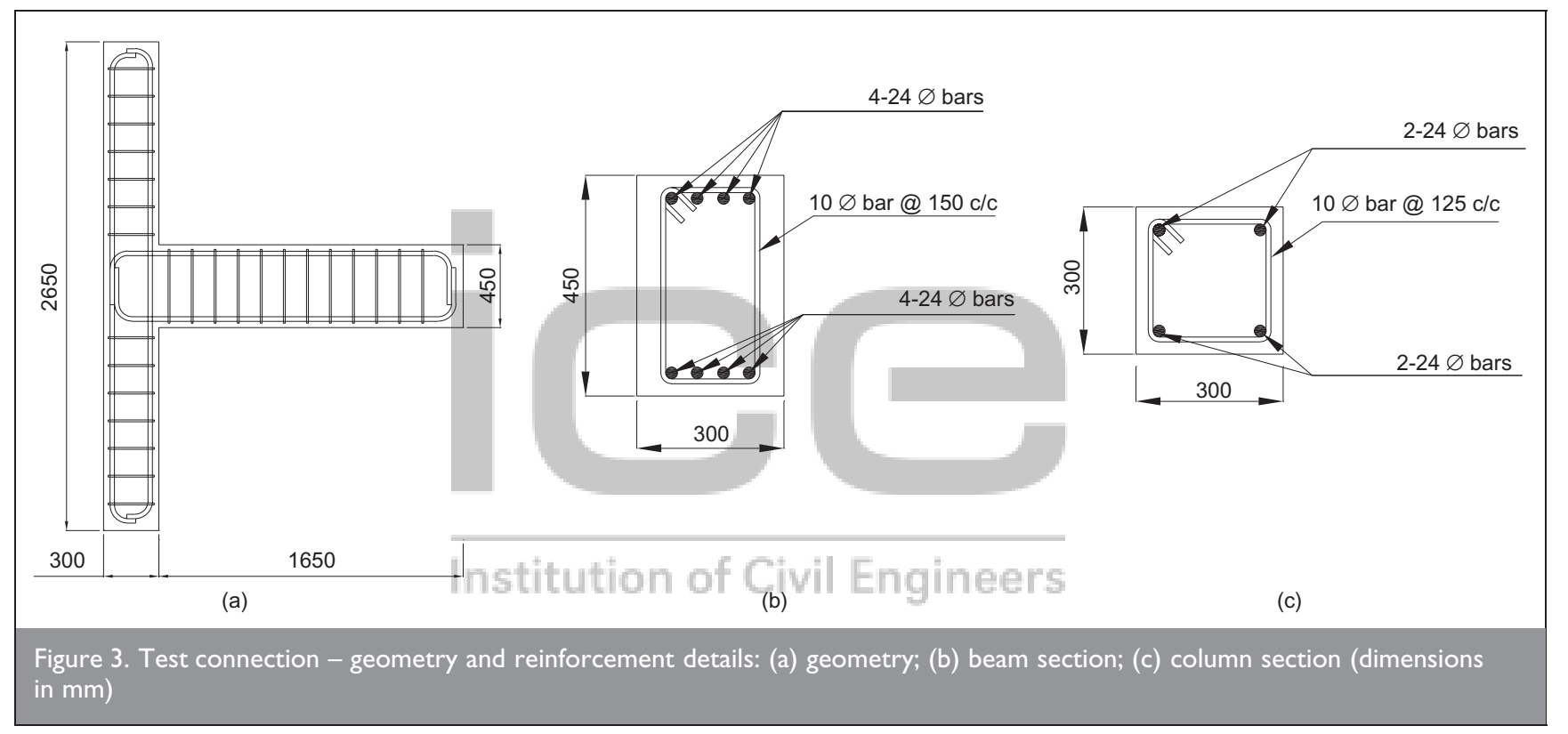

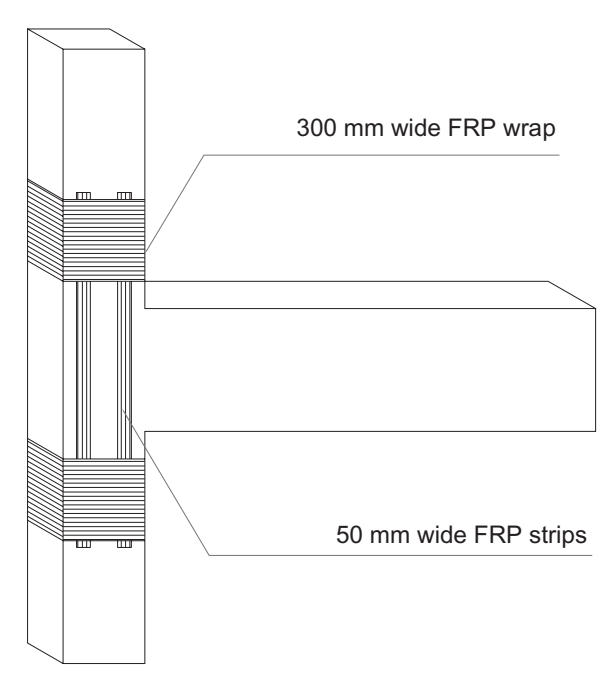

(a)

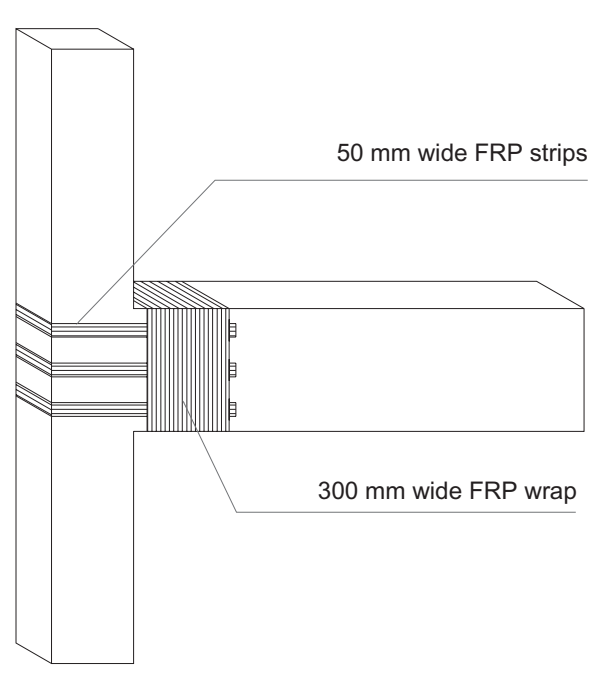

(b) 


\subsection{Material properties}

Properties of concrete on the day of the corresponding connection test are given in Table 2 and were tested in accordance with AS1012. ${ }^{13}$ The yield stresses of the longitudinal and transverse reinforcement were $532 \mathrm{MPa}$ and $332 \mathrm{MPa}$, respectively, as obtained from tensile tests on three test coupons in accordance with ASTM ES-04. ${ }^{14}$ The modulus of elasticity, tensile strength and ultimate strain of the FRP (nominal carbon fibre sheet thickness of $0.117 \mathrm{~mm}$ ) was determined from tests on five $15 \mathrm{~mm}$ wide two-layered FRP coupons in accordance with ATSM 3039/D3039M ${ }^{15}$ and found to be $243 \mathrm{GPa}, 3120 \mathrm{MPa}$ and $1 \cdot 1 \%$, respectively.

\subsection{Test set-up, instrumentation and experimental procedure}

Connections were tested with the column component orientated parallel to the ground and load applied to the free end of the vertically orientated beam as shown in Figure 5 . The connection was mounted on a stiff test rig with hinge supports at both ends of the column. An axial load of $180 \mathrm{kN}$ (equal to $8 \%$ of the gross axial load capacity of the column and representative of a typical floor load) was applied to the column using a hydraulic jack attached to one end of the column through a system of high-strength Macalloy bars. For the first set of connections (UM1, SM1 and SM2), which were tested under monotonically increasing load, load was applied in increments of $10 \mathrm{kN}$ steps and cracks were marked at every load step until no new cracks were observed after which the connections were loaded to failure. For the second set of connections (UC1 and SC1), load was applied to the beam tip in increasing steps of $5 \mathrm{~mm}$ deflection in each cycle in each push-pull direction. The deflection step was increased to $10 \mathrm{~mm}$ after the 8th cycle for FRP-strengthened connection SC1 owing to no significant change in the load. Cracks were marked on the test specimen at the peak deflection in each push and pull cycle until no new cracks were observed. The load was applied using a deflection controlled mode in all tests at a loading rate of $0.2 \mathrm{~mm}$ per second.

Twelve LVDTs were utilised; three to measure deflection along the length of the beam while the remainder were used for monitoring reaction frame movements. The internal steel reinforcement was extensively instrumented with $5 \mathrm{~mm}$ gauge strain gauges. Additional gauges of $5 \mathrm{~mm}$ gauge length were also applied on the FRP surfaces for the FRP-strengthened connections. Seven strain gauges were attached on each FRP strip on the front face and three gauges each on the back face for connections strengthened with column strips (Figure 6(a)) and nine gauges on each FRP strip (five on the front, two on the back and two on the side face) for the connection strengthened

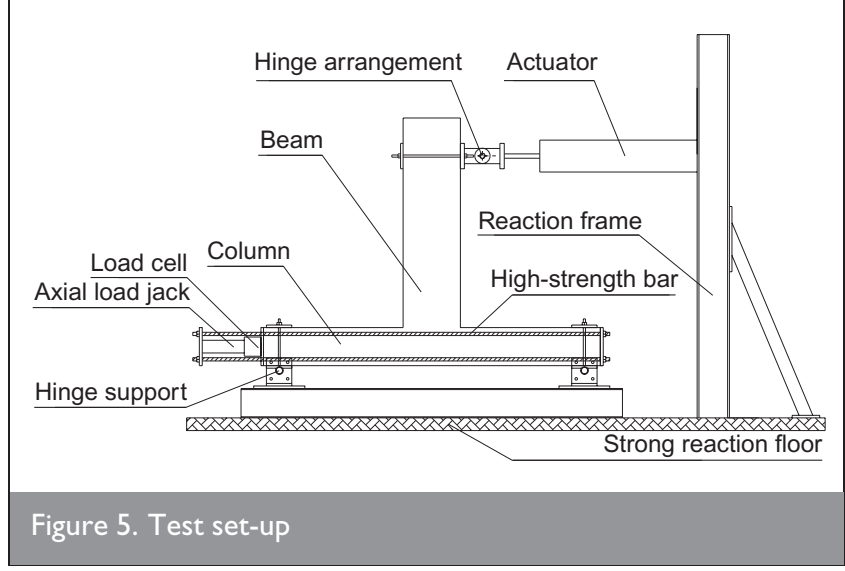

with beam strips (Figure 6(b)). Figure 6 also shows the reference point from where the location of these gauges was measured. Steel reinforcement strain gauge layout and results are not reported in this paper but can be found in Shrestha. ${ }^{16}$

\section{EXPERIMENTAL RESULTS}

\section{I. Cracking behaviour and failure mode}

\subsubsection{Control connection UM1 (monotonic load). As the} connection was loaded, minor flexural cracks in the beam and cracks at the beam-column corner were followed by cracking in the joint region. Severe diagonal shear cracks were observed in the joint region at a load of $70 \mathrm{kN}(13.2 \mathrm{~mm}$ beam tip deflection but herein referred to as deflection). A peak load of $96 \cdot 4 \mathrm{kN}$ (27.7 mm deflection) was observed, following which the connection lost its load-carrying capacity owing to severe shear cracking in the joint region. The test was stopped shortly after the peak load was reached. The final crack pattern is shown in Figure 7(a) and idealised in Figure 2. The average shear crack was measured at $34^{\circ}$ to the horizontal (column) axis.

\section{Civil Engineers}

\subsubsection{FRP-strengthened connection SM1 (monotonic}

load). Some minor flexural cracks were observed in the beam as it was loaded up to $10 \mathrm{kN}$. Cracks developed at the beamcolumn corner at a load of $20 \mathrm{kN}$ (2 mm deflection), which propagated towards the joint centre with increasing load until it intersected the FRP then propagated along the direction of FRP. A diagonal crack was observed in the joint region as the load was increased from $70 \mathrm{kN}$ to $80 \mathrm{kN}$ (19 mm deflection) with simultaneous cracking heard indicating localised debonding of FRP. Last crack marking was carried out at a load of $90 \mathrm{kN}$, following which the specimen was loaded continuously to failure. The peak load of $103 \mathrm{kN}$ was achieved at a deflection of $32 \mathrm{~mm}$ when FRP strip 1 (refer to Figure 6(a) for strip numbering and location) debonded along its whole length followed by a loss of load-carrying capacity of the connection. The primary mode of failure was debonding of the FRP strips in the joint region followed by joint shear failure. Concrete spalling was also observed at the beamcolumn corner on the 


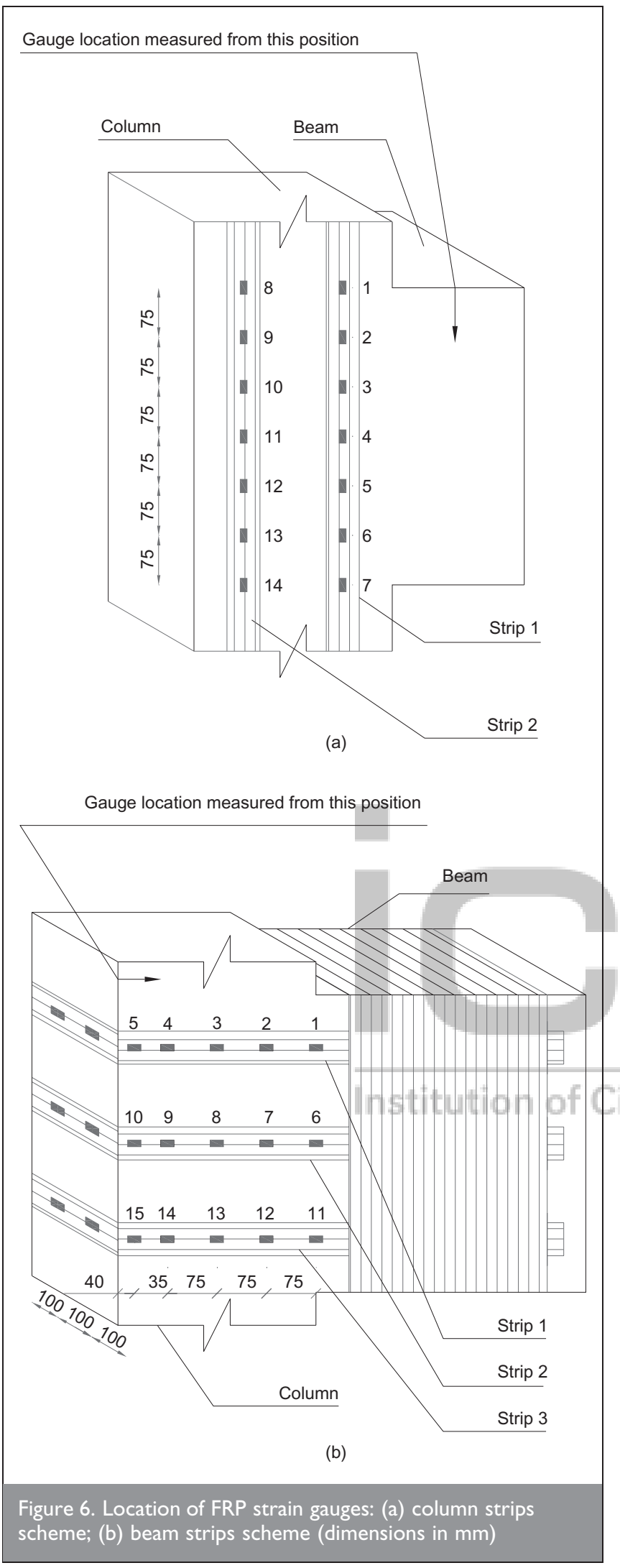

3.1.3. FRP-strengthened connection SM2 (monotonic load). A fine crack was observed at the beam-column corner at $10 \mathrm{kN}$ load, which propagated horizontally towards the beam centre and crossed the FRP strips with increasing load, while flexural cracks were observed in the beam. Unlike connection SM1, severe diagonal cracking in the joint region was not observed until the load reached $80 \mathrm{kN}$ (11.5 mm deflection). This was attributed to the confining action provided by the FRP strengthening where the FRP strips around the column and anchored by the FRP wrap provided some restraint against joint shear distortion. At $80 \mathrm{kN}$ load (11.5 mm deflection), local debonding of strip 3 (refer to Figure 6(b) for strip numbering and location) was observed and the load dropped. The last crack marking was carried out at $90 \mathrm{kN}$ load ( $14 \cdot 7 \mathrm{~mm}$ deflection) where diagonal shear cracking was observed to form in the joint region, following which the connection was loaded continuously. A peak load of $122 \mathrm{kN}$ was achieved at a deflection of $39 \cdot 1 \mathrm{~mm}$ when FRP strip number 3 debonded. This was followed by debonding of FRP strips 2 and 1 . The connection lost its load-carrying capacity considerably as a result of shear failure, which was followed by debonding along the length of all three FRP strips. Spalling of concrete at the beam-column corner on the compression face was also observed. Sequential rupture of FRP strips 3, 2 and 1 occurred as the loading was continued at load/deflection of $98 \mathrm{kN} / 67 \mathrm{~mm}$, $81 \mathrm{kN} / 81.5 \mathrm{~mm}$ and $62 \mathrm{kN} / 92 \mathrm{~mm}$ respectively. The final crack pattern is shown in Figure 7(c) and the average shear crack angle was measured to be at $30^{\circ}$ to the column axis.

3.1.4. Control connection UC1 (cyclic load). Diagonal shear cracks in the joint region and flexural cracks in the beam were observed as the first load cycle was applied. Subsequent load cycles resulted in formation of diagonal shear cracks with increased opening. A peak load of $83.2 \mathrm{kN}$ (at $29 \cdot 8 \mathrm{~mm}$ deflection in the 6th cycle) in the push direction was observed. The connection failed by joint shear failure and the final crack pattern in the joint region is shown in Figure 8(a). The average shear crack angle was measured at $28^{\circ}$ to the column axis.

\subsubsection{FRP-strengthened connection SC1 (cyclic load). Unlike} the control connection, only minor diagonal shear cracks in the joint region and flexural cracks in the beam were observed in the first cycle. Only in the second cycle did a major diagonal shear crack start to appear and first FRP debonding observed (at $72 \mathrm{kN}$ load and $8 \cdot 25 \mathrm{~mm}$ deflection in push direction). The FRP strengthening was effective in limiting the severity of cracking in the joint region and the strength degradation in subsequent load cycles was more gradual compared to the control connection UC1. A peak load of $97 \cdot 8 \mathrm{kN}$ (at $24 \cdot 4 \mathrm{~mm}$ deflection in the 5th cycle) in the push direction was observed when FRP strip 1 debonded. Ultimate failure was caused by major diagonal joint shear cracking following local debonding of the FRP strips. The column wraps at the ends of the FRP strips prevented the strips from completely debonding; however, the effectiveness of the FRP was lost following localised debonding. Figure 8(b) shows the final crack pattern in the joint. The average shear crack angle was measured to be at $38^{\circ}$ to the column axis. secured the ends of the FRP strips prevented the strips from completely debonding; however, the column wraps were not effective in preventing localised debonding in the joint region. The final crack pattern in the joint region is shown in Figure 7 (b) and the average shear crack angle was measured at $37^{\circ}$ to the column axis. No rupture of the FRP was observed and the FRP provided little restraint to opening of critical shear cracks.

\subsection{Load-deflection response}

3.2.1. Connections tested under monotonic load. The loaddeflection responses for FRP-strengthened connections SM1 and 


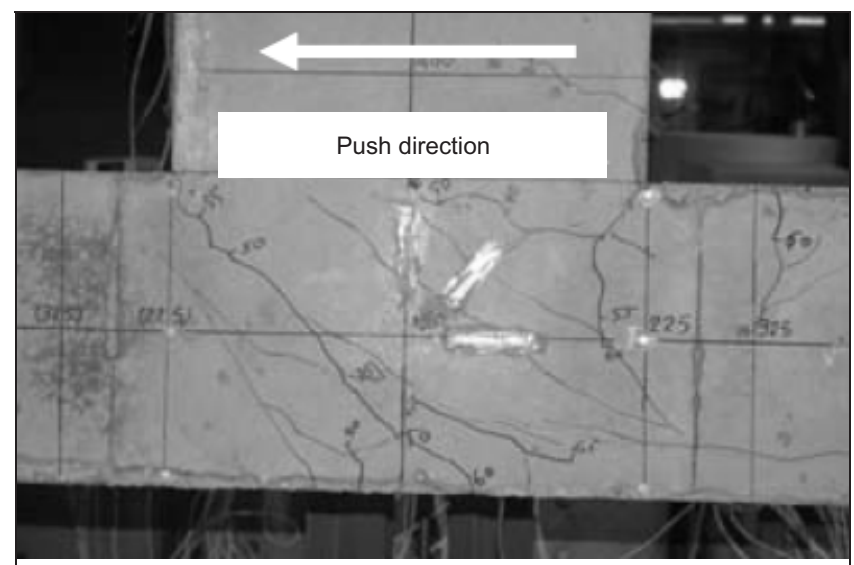

(a)

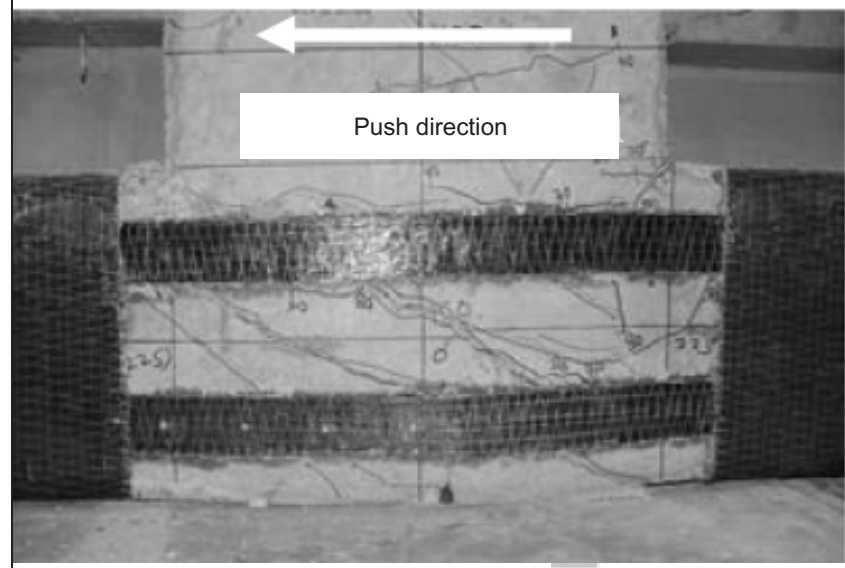

(b)

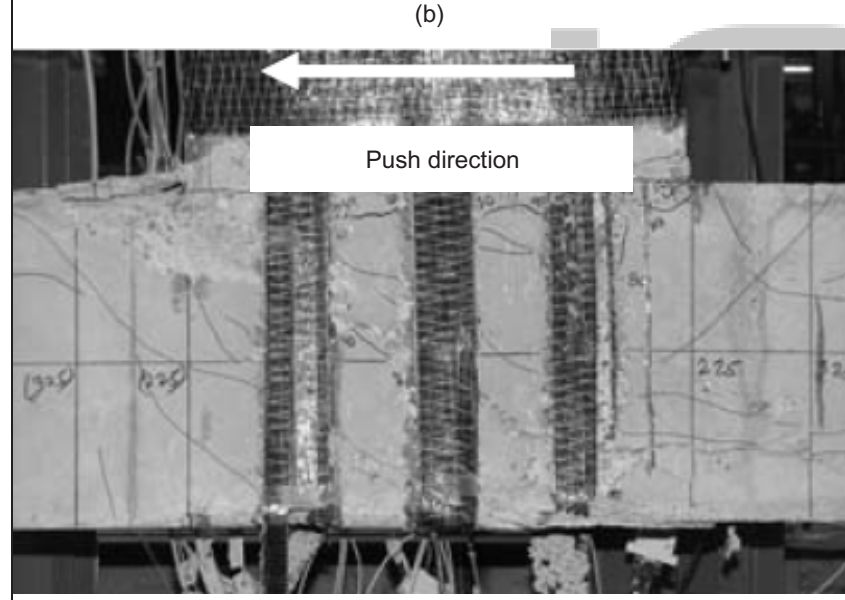

(c)

Figure 7. Final crack patterns for all connections tested under monotonic load: (a) connection UMI; (b) connection SMI; (c) connection SM2

SM2 are compared against the control connection UM1 in Figure 9 and the peak loads are summarised in Table 3. The comparison shows that the FRP strengthening enhanced the load-carrying capacity and the stiffness of the connections, the beam strips scheme (used on SM2) being more effective than the column strips scheme (used on SM1). This is not only because the two FRP strengthening schemes were designed with different amounts of FRP (but with the same FRP area to cross-sectional area ratio) but also because the beam strips scheme provided confinement in the joint region and restraint against joint rotation. Rupture of FRP on connection SM2, unlike connection SM1, also justifies the effectiveness of the beam strips. The strain distribution on FRP strips, discussed in the next section,

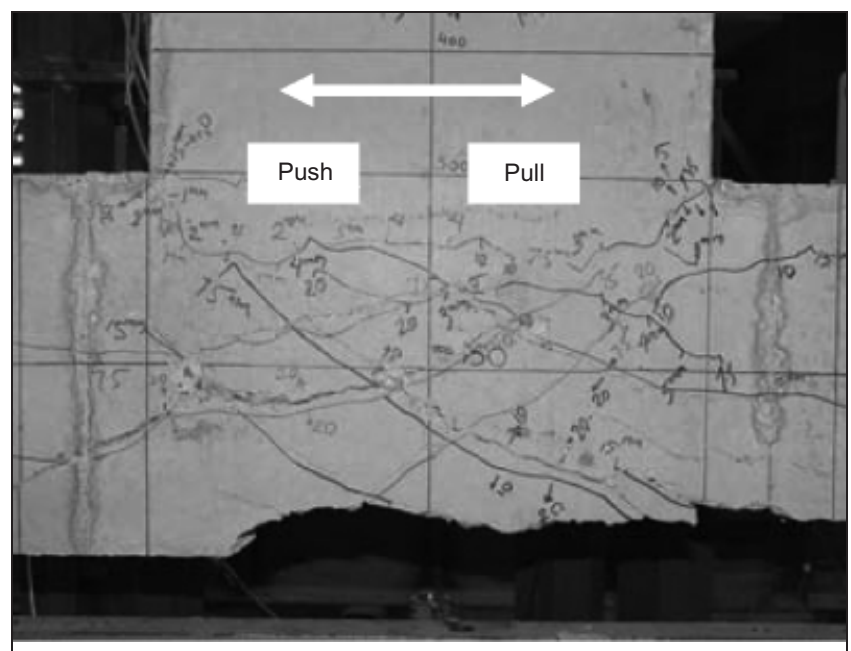

(a)

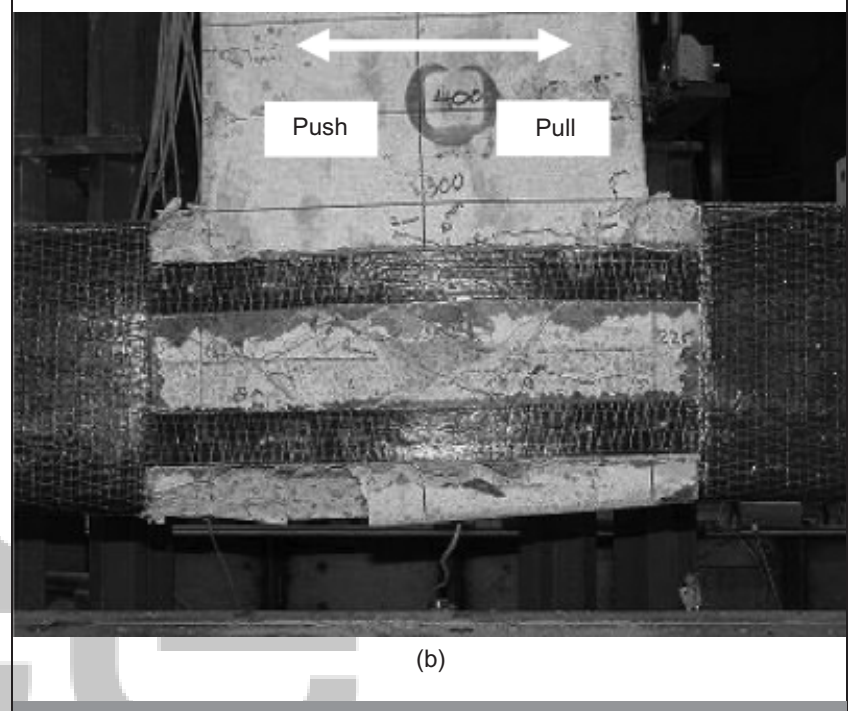

Figure 8. Final crack patterns for all connections tested under cyclic load: (a) control connection UCI; (b) FRP-strengthened connection $\mathrm{SCl}$

GIVII LIIIIITECIS

also shows that the capacity of beam FRP strips was utilised more effectively than the column FRP strips. However, the need for corner rounding at the column corners before FRP application to guard against possible stress concentration and subsequent FRP rupture makes the beam strip arrangement more labour intensive to implement in existing two-dimensional frames compared with the column strip arrangement.

\subsubsection{Connection tested under cyclic load. Load-deflection} responses for cyclic load tested connections UC1 and SC1 are shown in Figure 10 and the peak loads are summarised in Table 3. The FRP strengthening using column strips was effective in the cyclic load tests where the FRP resulted in enhancement of the load-carrying capacity of the connection by $17 \%$.

Comparison of peak-to-peak stiffness (Figure 11(a)) shows stiffness degradation to be more gradual in the FRP-

strengthened connection and the connection still had significant stiffness at a high deflection level. The FRP strengthened connection also showed better energy dissipation capacity compared with the control at higher deflection level (Figure 11(b)). The FRP strengthening was also effective in limiting the severity of the joint shear cracks based on visual inspection. Comparison of the peak load-deflection envelope for the control and FRP-strengthened connection is shown in Figure 12. 


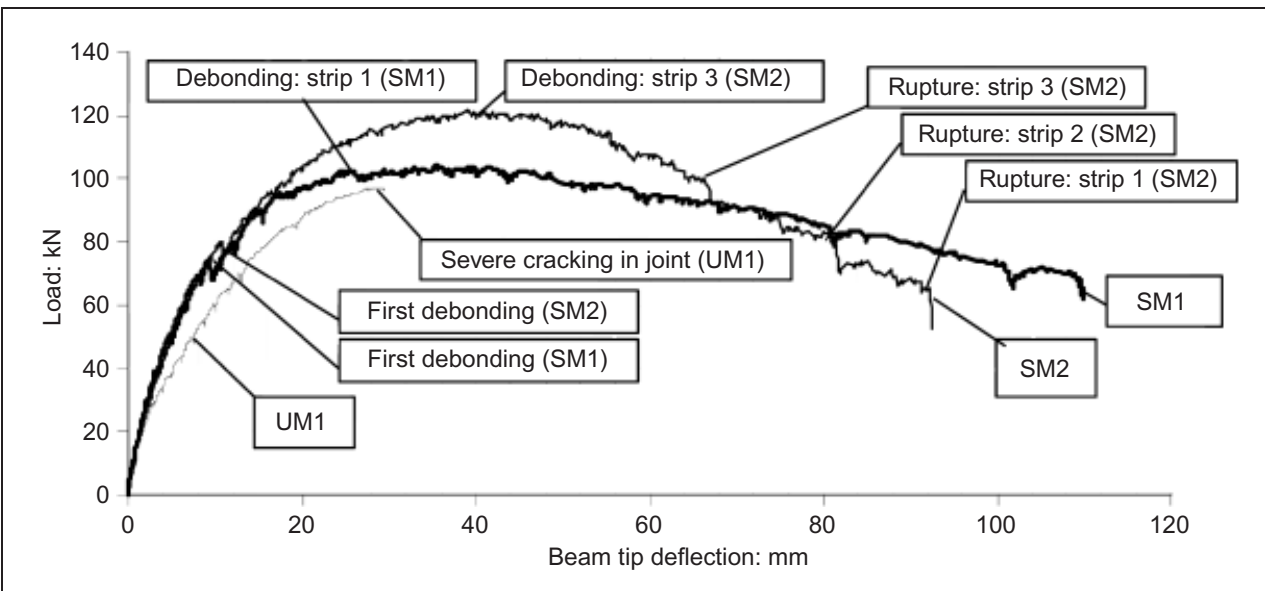

Figure 9. Load-deflection response for FRP-strengthened connections SMI and SM2 (monotonic load)

\begin{tabular}{|c|c|c|c|c|}
\hline Connection & $\begin{array}{c}\text { Peak load: } \\
\text { kN }\end{array}$ & $\begin{array}{l}\text { Deflection: } \\
\mathrm{mm}\end{array}$ & $\begin{array}{l}\text { Load increase: } \\
\qquad \mathrm{kN}\end{array}$ & $\begin{array}{c}\text { Load increase: } \\
\%\end{array}$ \\
\hline UMI & 96.4 & $27 \cdot 7$ & - & - \\
\hline SMI & 103 & 32 & 6.6 & $6 \cdot 8$ \\
\hline SM2 & 122 & 39.1 & $25 \cdot 6$ & $26 \cdot 6$ \\
\hline UCI (push/pull) & $83 \cdot 2 / 75 \cdot 0$ & $29 \cdot 8 / 33 \cdot 5$ & - & - \\
\hline SCI (push/pull) & $97 \cdot 8 / 87 \cdot 5$ & $24 \cdot 4 / 33 \cdot 4$ & $14 \cdot 6 / 12 \cdot 5$ & $17 \cdot 5 / 16.6$ \\
\hline
\end{tabular}

shear cracks intersected the FRP strips (indicated by the vertical dashed lines in Figures 13 and 14) have also been shown on the strain plots. In Figure 13 which shows the strains corresponding to loads ranging from $20 \mathrm{kN}$ to a maximum of $103 \mathrm{kN}$, high FRP strain can be observed in the region adjacent to shear cracks indicating debonding of FRP while low FRP strain regions are those where the bond between FRP and concrete was not lost and full interaction between the two was maintained. Similar behaviour can be seen in the FRP strain plots of connection SM2 as shown in Figure 14 where strain results corresponding to loads ranging from $20 \mathrm{kN}$ to a maximum of $122 \mathrm{kN}$ are shown. The reasonably uniform distribution of strain at high load in strip 1 of

\subsection{FRP strain results}

One of the key features of this study was the determination of strain distribution along the length of FRP strips in FRPstrengthened connections. Strain results of the FRP strengthening are discussed in this section.

The strain distribution for FRP strips 1 and 2 (refer to Figure 6(a) for strip location) in connection SM1 and strips 1,2 and 3 in connection SM2 (refer to Figure 6(b) for strip location) are shown in Figures 13 and 14 respectively. Positions where the

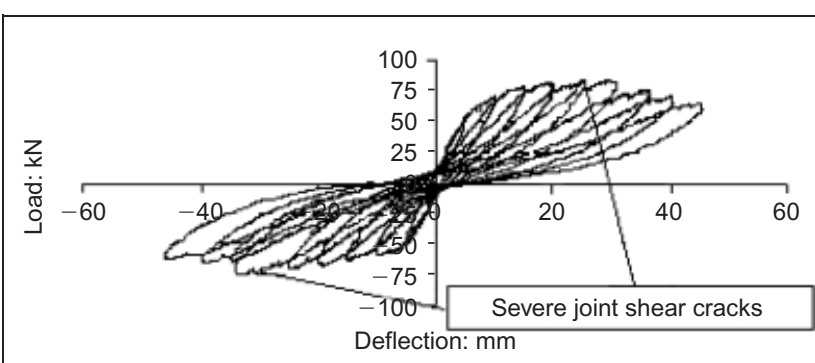

(a)

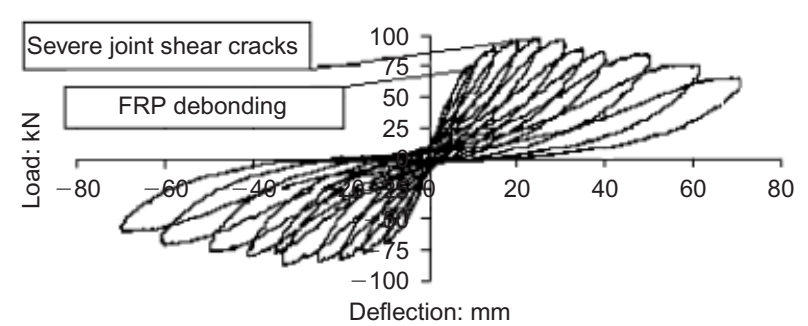

(b)

Figure 10. Load-deflection responses for cyclically loaded connections: (a) control UCI; (b) FRP-strengthened SCI connection SM2 (Figure 14(a) and to a limited degree in Figure 14(b)) indicates the strip has debonded along a significant portion of its length. Also, even though the final mode of failure in FRP was by rupture in connection SM2, the full rupture strain ( $1 \cdot 1 \%$ obtained by coupon test) was never attained, primarily due to the bending of FRP strips around the edge of the joint region. Such a phenomenon has been observed in FRP shear-strengthened beams ${ }^{18}$ and confined prismatic columns ${ }^{19}$ in which the FRP has been wrapped around a bend or corner.

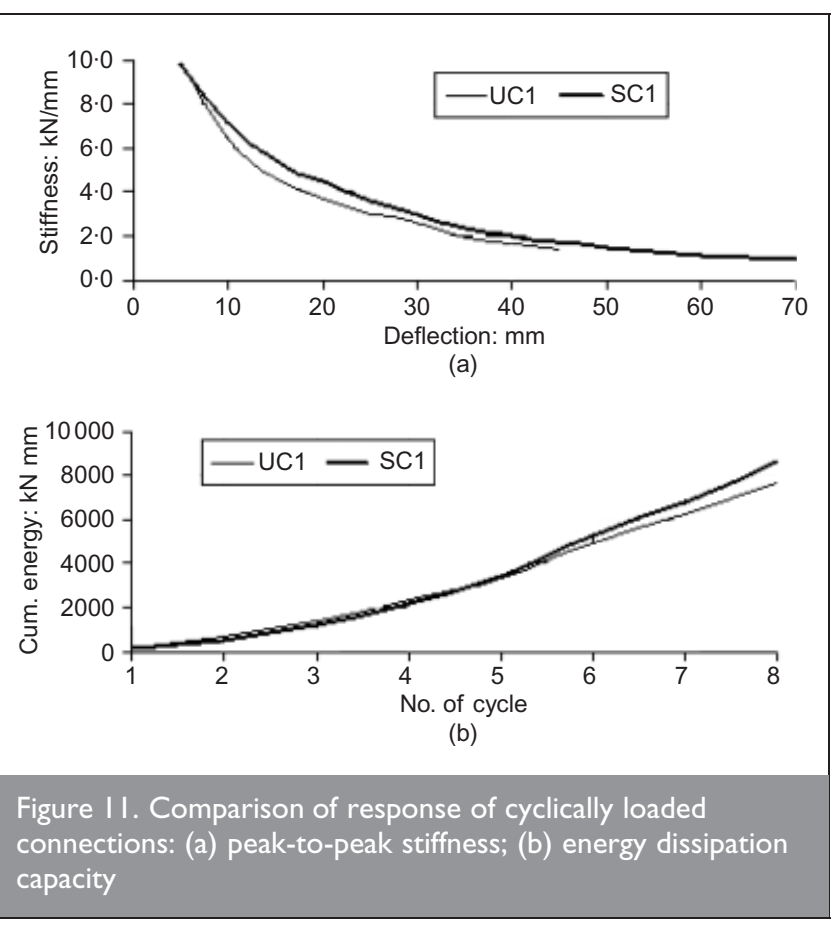




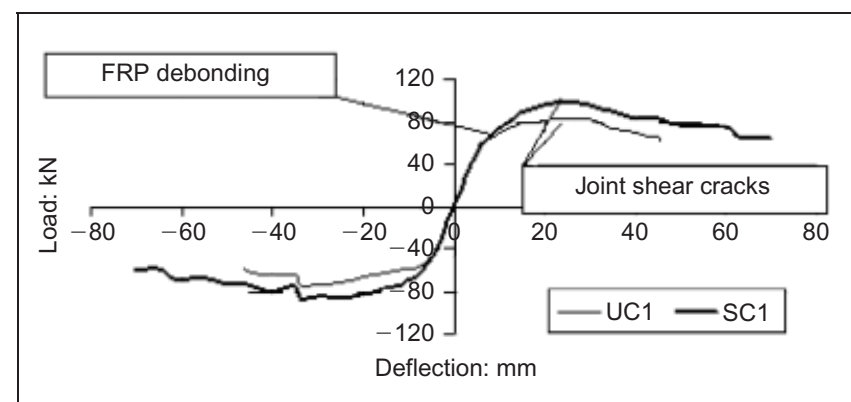

Figure 12. Comparison of peak load-deflection envelope for cyclically loaded connections

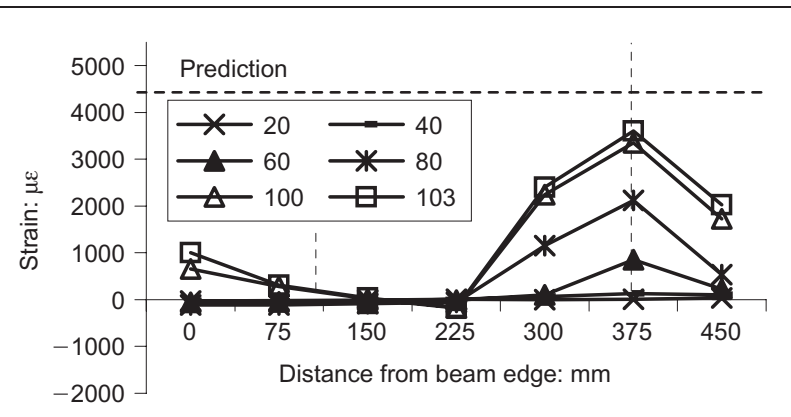

(a)

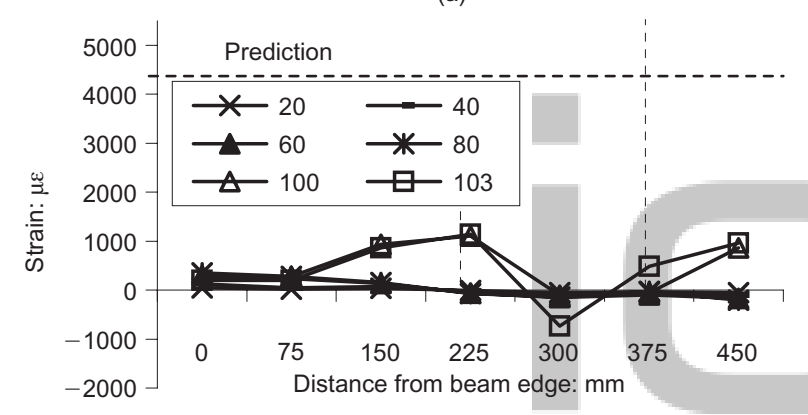

(b)

Figure 13. Distribution of strain along length of each FRP column strip for connection SMI (vertical dashed lines indicate shear cracks at FRP position prediction according to Chen and Teng ${ }^{17}$ ): (a) strip I; (b) strip 2

The strain distribution for strips 1 and 2 for the cyclically loaded strengthened connection (SC1) at different beam tip deflection levels (up to peak load) is shown in Figure 15 for push and pull directions showing results corresponding to deflections ranging from 5 to $30 \mathrm{~mm}$. The positions where shear cracks intersected the FRP strips are again represented as vertical dashed lines. High strain was recorded on the FRP adjacent to the intersection of the FRP with the joint shear cracks; adjacent low strain signifying no debonding or compressed regions. Constant strain readings along approximately half the length of strip 1 for the pull cycle, as well as the push cycle, for connection SC1 signifies virtual complete debonding of the strip. Comparing these strain plots with strain plots for connection SM1 tested under monotonic load, difference in distribution of strain can be observed. In connection SM1, relatively higher strain values were observed in strip 1 compared with strip 2 indicating that strip 1 was the main shear resisting strip. However, such a difference in strain results for the cyclic load test was not observed, which may be due to more cracking in the joint region under cyclic loading. Deterioration of bond between reinforcement bars and concrete due to cyclic loading may also

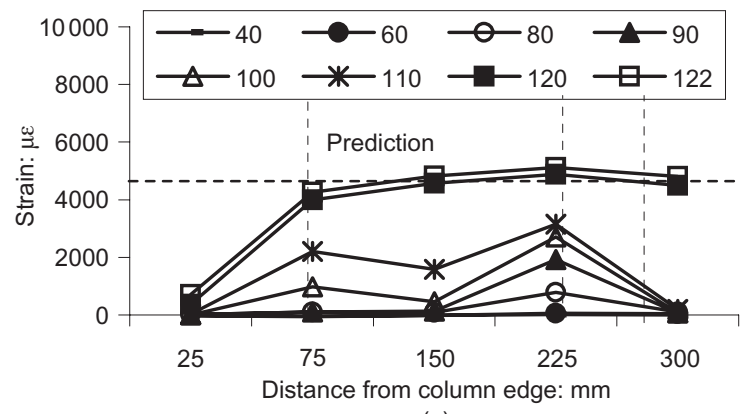

(a)

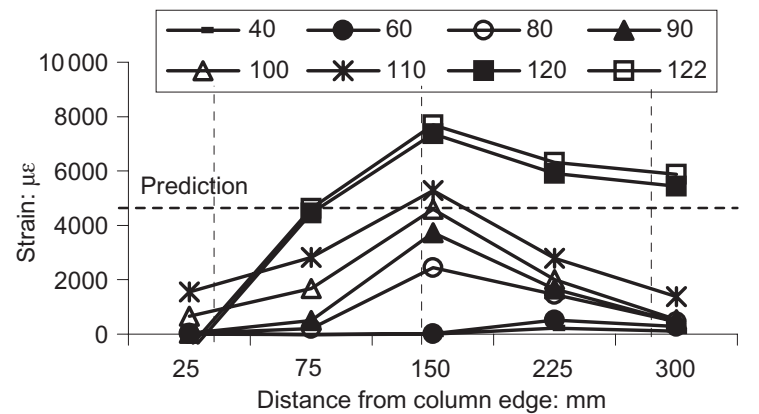

(b)

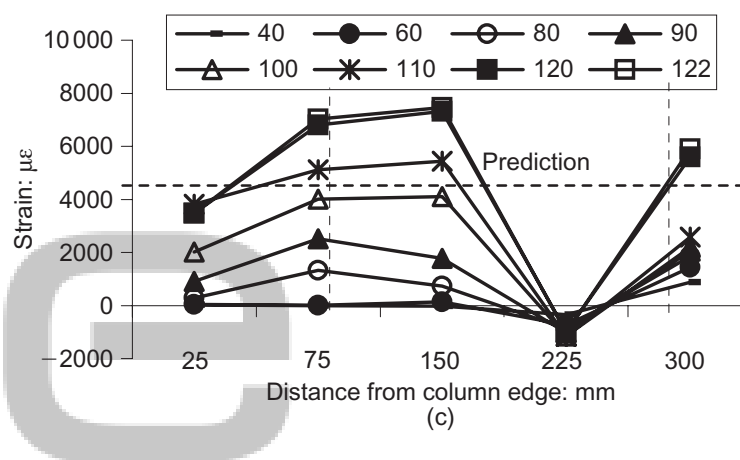

Figure 14. Distribution of strain along length of each FRP beam strip for connection SM2 (vertical dashed lines indicate shear cracks at FRP position prediction according to Chen and Teng ${ }^{17}$ ): (a) strip I; (b) strip 2; (c) strip 3

have led to more active participation of strip 2 in connection SC1.

\section{ANALYTICAL MODELLING}

An analytical model is presented in this section which accounts for the contribution of the FRP to the shear strength of the joint. The method used to calculate the principal joint shear stress is initially described.

\section{I. Calculation of joint stress}

The free body diagram for the test connection as well as the joint forces is shown in Figure 16. Horizontal equilibrium of the joint forces in Figure 16(b) above the beam centreline leads to the following relationship for the horizontal joint shear force, $V_{\mathrm{jh}}$.

$$
\begin{array}{|c|l}
\hline \text { I } & V_{\mathrm{jh}}=T_{\mathrm{b}, \mathrm{s}}+T_{\mathrm{b}, \mathrm{frp}}-V_{\mathrm{col}}=T_{\mathrm{b}}-V_{\mathrm{col}}
\end{array}
$$

where $T_{\mathrm{b}, \mathrm{s}}$ and $T_{\mathrm{b} \text {,frp }}$ are the tensile force due to steel reinforcement and FRP. The quantities $T_{\mathrm{b}}$ and $V_{\text {col }}$ represent the total tensile forces transferred to the joint and the column shear force, respectively. $V_{\text {col }}=M_{\mathrm{j}, \text { centre }} / L_{\mathrm{c}}$ where $M_{\mathrm{j} \text {,centre }}$ and 


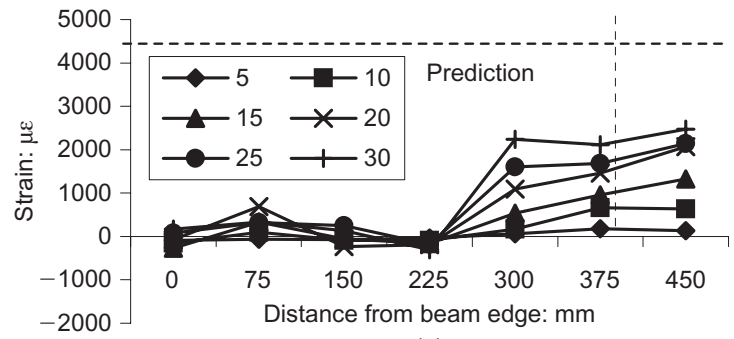

(a)

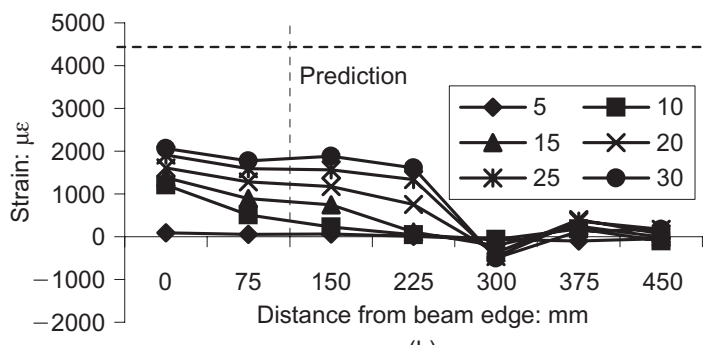

(b)

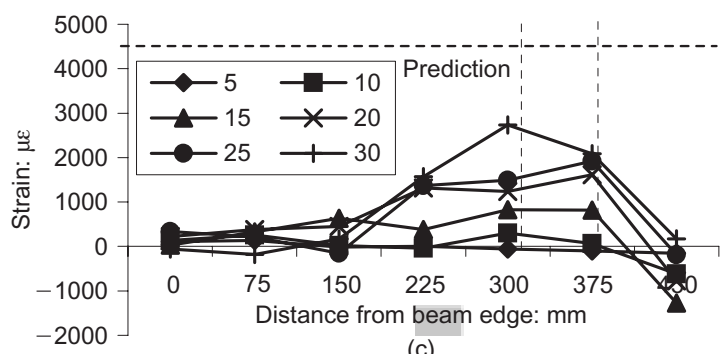

(c)

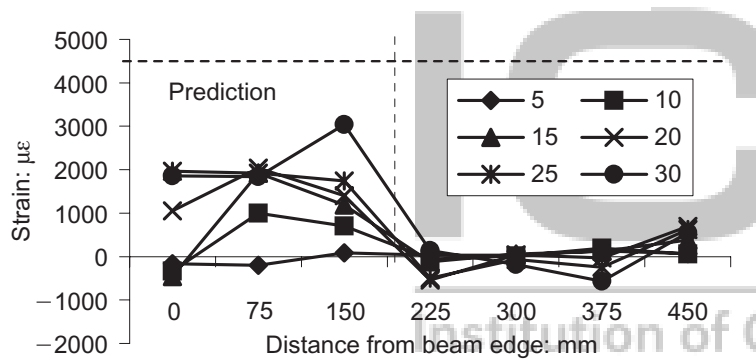

(d)

Figure 15. Distribution of strain along length of each FRP column strip for connection $\mathrm{SCI}$ (vertical dashed lines indicate shear cracks at FRP position prediction according to Chen and Teng ${ }^{17}$ )

$L_{\mathrm{c}}$ are moment at the joint centre and length of the column between points of contra-flexure, respectively, and $M_{\mathrm{j}, \text { centre }}=P_{\mathrm{b}} \times L_{\mathrm{b}}$ where $P_{\mathrm{b}}$ and $L_{\mathrm{b}}$ are beam tip load and its lever arm from the column centreline respectively. A similar expression to Equation 1 can be obtained for the vertical joint shear force by considering the vertical equilibrium of the joint, however, owing to the multilayered arrangement of the column reinforcement the derivation is tedious. The vertical joint shear force can be calculated as follows as per Paulay and Priestley ${ }^{20}$

\begin{tabular}{|l|l|}
\hline 2 & $V_{\mathrm{jv}}=\frac{V_{\mathrm{jh}}}{b} h$ \\
\hline
\end{tabular}

where $b$ and $h$ are column width and beam depth respectively. The horizontal and vertical joint shear stresses, which are complimentary shear stresses, can then be calculated using a single expression, given as follows where $d$ is the column depth

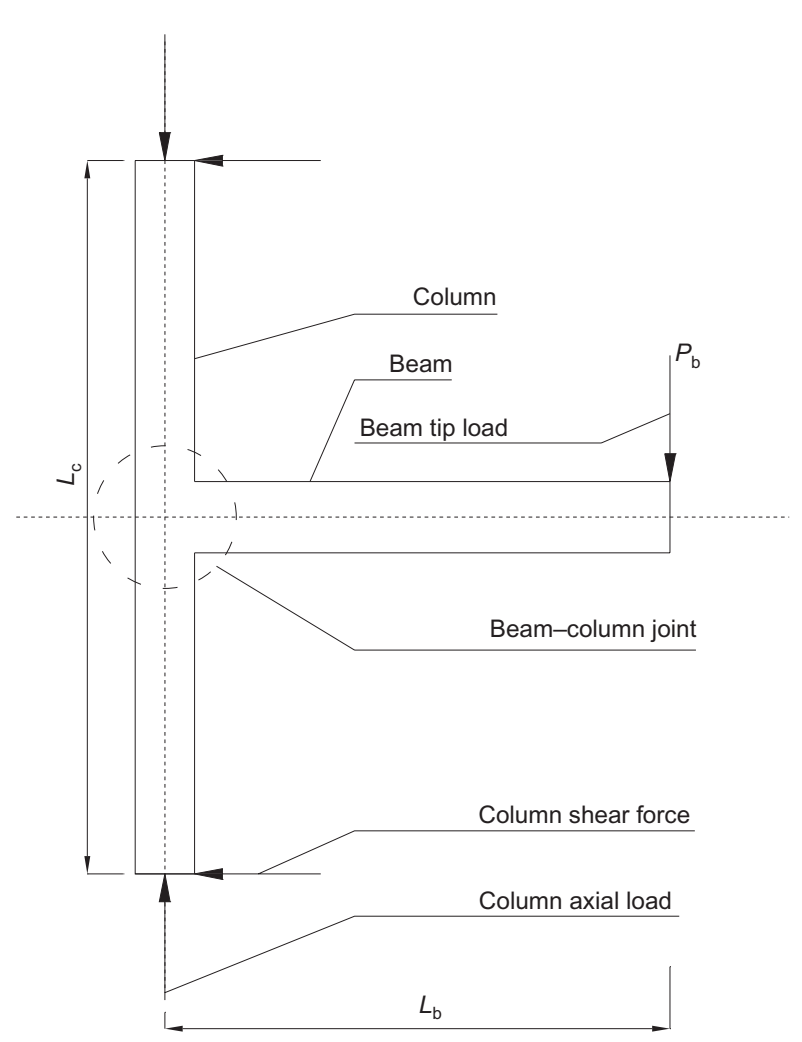

(a)

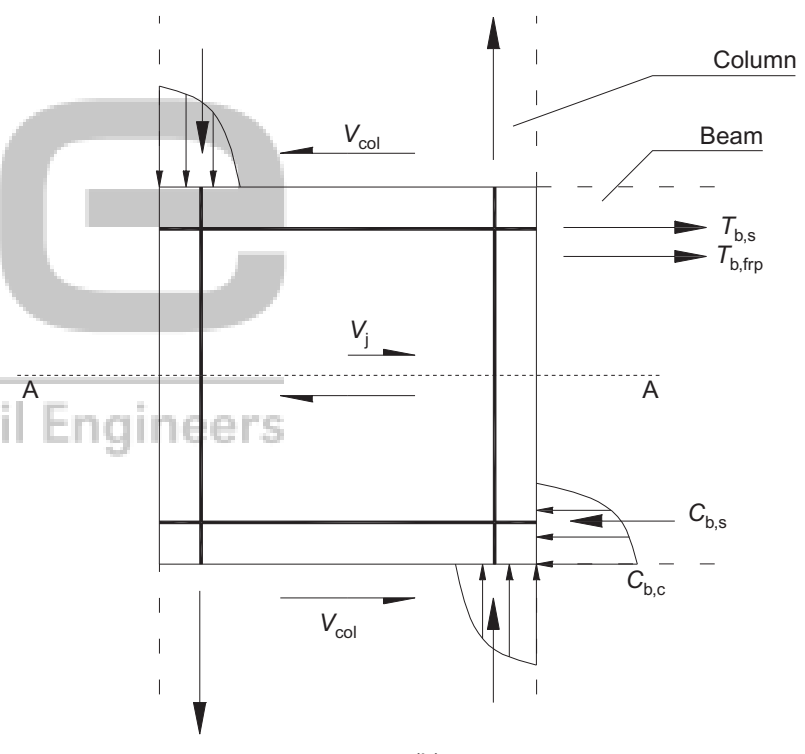

(b)

Figure 16. Connection dimensions and forces: (a) exterior beam-column connection; (b) enlarged view of joint region forces

$$
3
$$

Based on the stress state represented in Figure 17, the joint stress perpendicular to the major shear crack $\left(v_{\mathrm{j}}\right)$, which is the principal stress, can be calculated as follows

$$
v_{\mathrm{j}}=\frac{\sigma_{\text {axial }}}{2}+\sqrt{\left(\frac{\sigma_{\text {axial }}}{2}\right)^{2}+\left(v_{\text {jh }}\right)^{2}}
$$




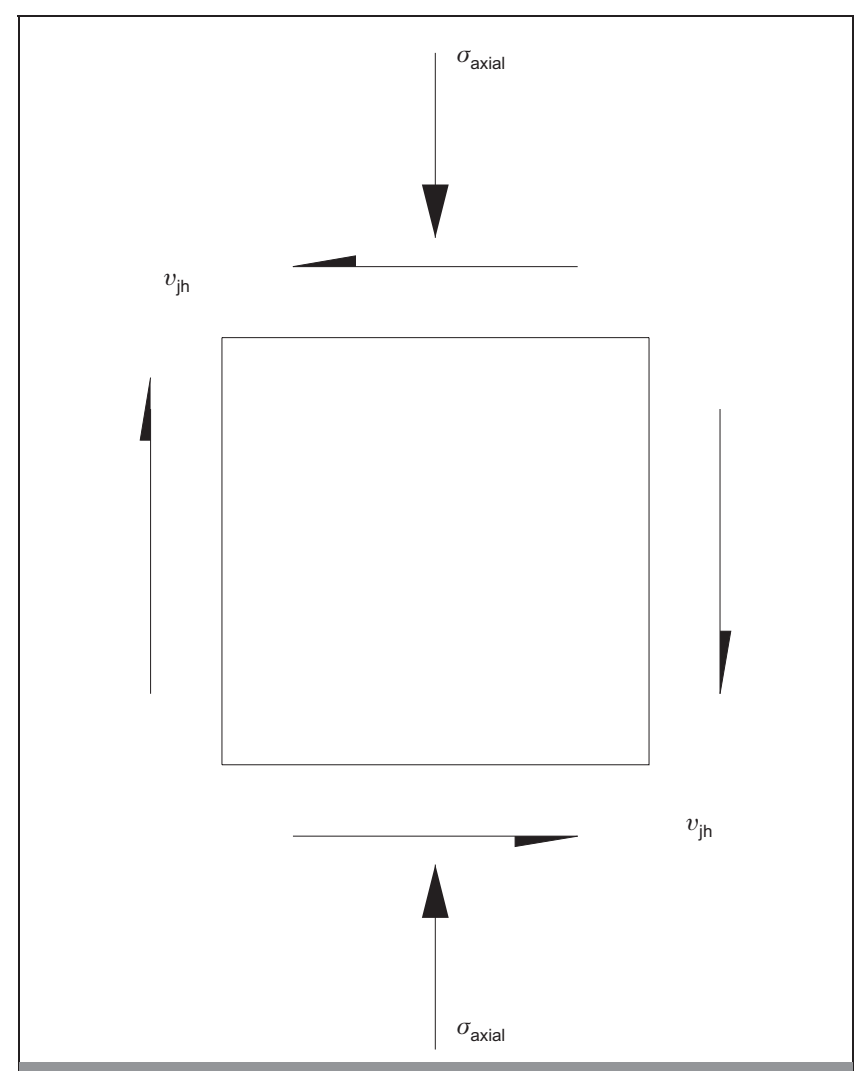

Figure 17. Joint stresses

where $\sigma_{\text {axial }}$ is the axial stress in the column and has a negative sign when the column is subjected to compressive stress.

In determining $V_{\mathrm{jh}}$, calculation of tensile force, $T_{\mathrm{b}}$, requires a standard section analysis of the beam at the beam-column interface, based on iterating upon the extreme concrete compression fibre strain $\left(\varepsilon_{\mathrm{cf}}\right)$ until the sectional flexural strength equals the bending moment at the same section owing to the beam tip load. A number of key standard assumptions are adopted in this analysis namely

(a) elastic-perfectly-plastic stress-strain relation for steel and elastic behaviour of FRP

(b) contributions of concrete in tension and FRP in compression are neglected

(c) for FRP strips applied to the beam sides, the total FRP area is assumed to be smeared across the width of the FRP such that the effect of FRP in the compression zone is ignored. Depending upon the load and hence the moment at the beam section, the concrete could be either in an elastic or inelastic state.

The joint shear stress for all tested connections is summarised in Table 4. As all the connections were cast from the same concrete batch and had near identical concrete strengths at testing, the increment in the joint shear stress of FRPstrengthened connections is calculated as the difference in the joint shear stress between the control and FRPstrengthened connections.

\subsection{Analytical model for FRP contribution to joint} strength

The primary mode of failure for both FRP-strengthened connections, SM1 and SM2, was by debonding of the FRP strips. For connection SM1, debonding of strip 1 occurred at the peak load following which the load-carrying capacity of the connection dropped. Similarly, the load-carrying capacity of connection SM2 was subsequently lost following debonding of strip 3. As such, the debonding strain of the FRP is more critical than the FRP rupture strain. Chen and Teng's ${ }^{17}$ bond strength model, initially developed for determining the shear strength of FRP-to-concrete joints, is used in the present study to predict debonding of FRP in the joint (refer to Equation 5). This bond strength model has also been used to predict debonding in FRP shear- ${ }^{21}$ and flexurally strengthened RC beams. ${ }^{22}$ The fundamental similarity between the lap-shear tests with which Chen and Teng's ${ }^{17}$ bond strength model was derived, and the FRP-strengthened connections being reported herein, is the opening of intermediate crack/s in the joint causing debonding (i.e. IC debonding) of the FRP. A detailed description of the applicability of Chen and Teng's ${ }^{17}$ model to modelling IC debonding is given in Teng et al. ${ }^{22}$

$$
5 \quad \sigma_{\mathrm{p}}=\alpha \beta_{\mathrm{p}} \beta_{1} \sqrt{E_{\mathrm{p}} \sqrt{f_{\mathrm{c}}^{\prime}} / t_{\mathrm{p}}}
$$

The parameters $\alpha, \beta_{\mathrm{p}}, \beta_{\mathrm{l}}, E_{\mathrm{p}}, f_{\mathrm{c}}^{\prime}$ and $t_{\mathrm{p}}$ represent an empirical factor (best-fit model $=0 \cdot 427$ ), FRP width factor, FRP length factor, modulus of elasticity of FRP, compressive strength of concrete and FRP thickness respectively. The FRP width factor is $\sqrt{\left(2-b_{\mathrm{p}} / b_{\mathrm{c}}\right)\left(1+b_{\mathrm{p}} / b_{\mathrm{c}}\right)}$, where $b_{\mathrm{p}}$ and $b_{\mathrm{c}}$ represent the widths of the FRP and concrete respectively. In the case of the FRP-strengthened joint region, $b_{\mathrm{c}}$ represents the centre to centre distance between the FRP strips. The FRP length factor is governed by the length of FRP bonded to concrete and is taken as 1 as the debonded length of FRP at peak load was greater

than the effective bond development length. The input parameters are the same for connections SM1, SM2 and SC1, namely, $b_{\mathrm{p}}=50 \mathrm{~mm}, b_{\mathrm{c}}=150 \mathrm{~mm}, E_{\mathrm{p}}=243000 \mathrm{MPa}$ and $t_{\mathrm{p}}=0 \cdot 234 \mathrm{~mm}$, except for $f_{\mathrm{c}}^{\prime}(25 \cdot 6 \mathrm{MPa}$ for SM1 and SM2; 25.8 MPa for SC1), which results in stresses of $1094 \mathrm{MPa}$ and $1096 \mathrm{MPa}$ respectively. Note that the width of concrete considered effective for each strip is the same for all strengthened connections (i.e. two strips across the $300 \mathrm{~mm}$ column width for SM1 and SC1, and three strips down the depth of the $450 \mathrm{~mm}$ deep beam for SM2).

The following analytical model, which allows the contribution of FRP to the shear strength of a joint failing by debonding of the FRP to be calculated, is based upon consideration of equilibrium of stress in the FRP crossing the principal plane in

\begin{tabular}{|c|c|c|c|c|}
\hline Connection & $\begin{array}{l}\text { Peak load: } \\
\text { kN }\end{array}$ & $\begin{array}{l}\text { Joint shear force: } \\
\qquad \mathrm{kN}\end{array}$ & $\begin{array}{l}\text { Joint stress: } \\
\qquad \mathrm{MPa}\end{array}$ & $\begin{array}{l}\text { Increment: } \\
\mathrm{MPa}\end{array}$ \\
\hline UMI & 96.4 & 359.8 & $3 \cdot 12$ & - \\
\hline SMI & 103 & $387 \cdot 3$ & $3 \cdot 40$ & 0.28 \\
\hline SM2 & 122 & 462.7 & $4 \cdot 24$ & 1.12 \\
\hline UCI (push/pull) & $83 \cdot 2 / 75 \cdot 0$ & 292.5 & $2 \cdot 4$ & - \\
\hline SCI (push/pull) & $97 \cdot 8 / 87 \cdot 5$ & $366 \cdot 1$ & $3 \cdot 18$ & 0.78 \\
\hline
\end{tabular}


the joint. A similar approach has been used previously by others to develop such a model (e.g. Chen and Teng's ${ }^{21}$ model for the prediction of the FRP contribution to FRP shear strengthened RC beams) and full details of the derivation of the model is given in Shrestha ${ }^{16}$

\begin{tabular}{|l|l|}
\hline & $v_{\text {frp }}=\frac{1}{b d} \sum_{i=1}^{n} \frac{\left[A_{\mathrm{frp}, i} \cdot f_{\mathrm{frp}, \mathrm{deb}, i} \sin (\beta+\theta)\right]}{\sin \theta}$ \\
\hline
\end{tabular}

In Equation 6 (and in reference to Figure 18) $\theta$ is the angle between the critical diagonal (shear) crack and column axis, $n$ is the number of strips of FRP, $\beta$ is the orientation of the FRP strip to the column axis, $b$ and $d$ are joint width and depth and $f_{\text {frp,deb, } i}$ and $A_{\text {frp, } i}$ are the stress in the FRP at debonding and cross-sectional area of FRP strip crossing the joint.

\subsection{Comparison of analytical model to test results} The strain value of approximately $4500 \mu \varepsilon$ corresponding to a debonding stresses of $1094 \mathrm{MPa}$ and $1096 \mathrm{MPa}$ is shown in the strain plots of SM1 in Figure 13, SM2 in Figure 14 and SC1 in Figure 15. The FRP strips debonded at a much lower strain than the calculated debonding strain for connections SM1 and SC1, while the FRP strip debonded at a much higher strain than the calculated strain for connection SM2. The difference in the debonding strain observed in the test and calculated using Chen and Teng ${ }^{17}$ model could be attributed to a number of factors such as

(a) Chen and Teng's ${ }^{17}$ model is based on regression of dispersed test data

(b) fundamental difference between the idealised shear tests used to formulate and calibrate Chen and Teng's ${ }^{17}$ model to the more complex debonding mechanism in the FRPstrengthened connection tests

(c) non-uniform distribution of strain across the width of the FRP such that the FRP fibre closest to the shear crack would have the maximum strain

(d) angle at which the shear cracks intersect the FRP strips

(e) end anchorage of FRP and confinement has a significant effect on the strain level in the FRP, such as in case of the

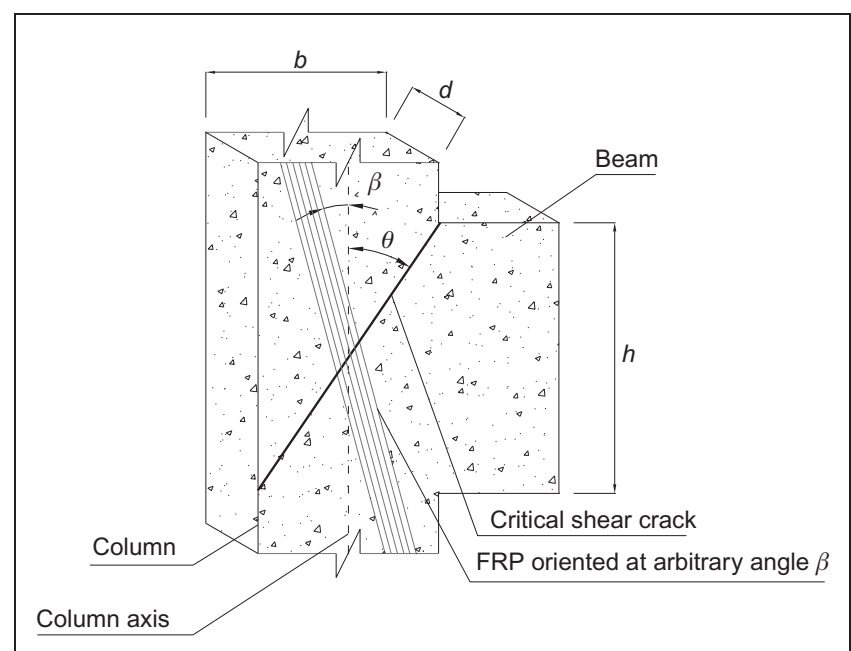

Figure 18. Joint portion of a reinforced concrete connection with an FRP strengthening applied at an arbitrary angle beam strips schemes where confinement provided by the FRP resulted in increased effectiveness of FRP strips.

Also, it should be noted that the strain gauges were not located exactly where the shear cracks intersected the FRP strips (as the location of the cracks cannot be pre-determined), and hence the recorded strain may only represent strain close to the peak strain values. However, the difference in the debonding strain values recorded during the test and calculated from Chen and Teng's ${ }^{17}$ model demonstrates the need to consider a correction factor, namely a suitable distribution factor to take into account all these factors.

Table 5 shows the results of Equation 6 when evaluated against the test data. The shear strength contributions of the FRP strengthening are calculated using debonding strain based on Chen and Teng's ${ }^{17}$ model and a shear crack angle $\theta$ of $45^{\circ}$. The proposed model overpredicted the shear strength contribution of FRP for connection SM1 by 4\% but gave a conservative prediction for connections SM2 and SC1. These observations lead to the conclusion that the strain in FRP needs to be adjusted by including a suitable distribution factor to take a number of factors into account as discussed earlier. As such, the proposed model is modified to include this distribution factor as given by Equation 7, where $D_{\text {frp }}$ is the distribution factor.

A suitable value of this distribution factor could be determined based on a regression analysis of a larger collection of similar tests. In addition to taking into account the non-uniform distribution of strain in the FRP strengthening, the distribution factor should also consider the effects of type of loading and end anchorage of FRP strengthening.

\begin{tabular}{|l|l|}
\hline & $v_{\text {frp }}=D_{\text {frp }} \frac{1}{b d} \sum_{i=1}^{n} \frac{\left[A_{\mathrm{frp}, i} f_{\mathrm{u}, i} \sin (\beta+\theta)\right]}{\sin \theta}$ \\
\cline { 2 - 3 } &
\end{tabular}

\section{CONCLUSIONS}

Two-dimensional exterior connections designed with no joint shear reinforcement were strengthened with simple and practical FRP strip schemes. Tests demonstrated the effectiveness of FRP in enhancing the load-carrying capacity and deformation of these connections when subjected to monotonic or cyclic loads. More important, however, the tests have enabled a deeper understanding of the strength and behaviour of the FRP. Beam or column wrapping at the ends of the FRP strengthening prevented complete debonding of FRP, however, the need to prevent localised debonding of FRP near the shear cracks was identified in order to enhance the effectiveness of the FRP strengthening. FRP strain results demonstrated the full capacity of the FRP could not be reached owing to progressive debonding of the FRP strips. An analytical model to predict the contribution of FRP to the joint shear strength was proposed and its predictions compared reasonably well with test data. Results suggest a distribution factor needs to be considered to take into account the nonuniform distribution of strain in FRP and variation in the FRP strain at failure which depends upon a number of factors such as type of loading and end anchorage of the FRP strengthening. Future research should address this issue. 


\begin{tabular}{|c|c|c|c|c|c|c|c|c|c|}
\hline Specimen ID & $b: \mathrm{mm}$ & $\mathrm{d}: \mathrm{mm}$ & $A_{\text {frp }}: \mathrm{mm}^{2}$ & $\begin{array}{c}f_{\text {frp,deb}}: \\
\mathrm{MPa}\end{array}$ & $\beta: \operatorname{deg}$ & $\theta: \operatorname{deg}$ & $\begin{array}{c}v_{\text {frp,model }}: \\
\mathrm{MPa}\end{array}$ & $\begin{array}{c}v_{\text {frp,test }}: \\
\mathrm{MPa}\end{array}$ & $\frac{v_{\text {frp }} \text { model }}{v_{\text {frp }} \text { test }}$ \\
\hline SMI* & 300 & 300 & $46 \cdot 8$ & 876 & 0 & 37 & 0.16 & 0.28 & 0.98 \\
\hline SM2* & 300 & 300 & $70 \cdot 2$ & 1776 & 90 & 30 & 0.6 & 1.12 & 1.02 \\
\hline $\mathrm{SCl} *$ & 300 & 300 & $46 \cdot 8$ & 810 & 0 & 38 & 0.16 & 0.78 & 0.32 \\
\hline $\mathrm{SMI}^{\dagger}$ & 300 & 300 & $46 \cdot 8$ & 1094 & 0 & 45 & 0.29 & 0.28 & 1.04 \\
\hline $\mathrm{SM} 2^{\dagger}$ & 300 & 300 & $70 \cdot 2$ & 1096 & 90 & 45 & 0.42 & $1 \cdot 12$ & 0.38 \\
\hline $\mathrm{SCl}^{\dagger}$ & 300 & 300 & $46 \cdot 8$ & 1094 & 0 & 45 & 0.29 & 0.78 & 0.36 \\
\hline
\end{tabular}

* Based on test debonding strain at peak load and observed crack angle

Based on strain result from Chen and Teng's ${ }^{17}$ model and crack angle of $45^{\circ}$

Table 5. Analytical model input data and results and comparison with test data

\section{ACKNOWLEDGEMENTS}

This project was funded by Australian Research Council (ARC) Discovery Grant DP0559567. The financial assistance of the ARC is gratefully acknowledged. The authors also acknowledge the assistance of the Structures Laboratory staff at the University of Technology Sydney in conducting the tests.

\section{REFERENCES}

1. Gergely J., Pantalides C. P. and Reavely L. Shear strengthening of RCT-joints using CFRP composites. Journal of Composites for Construction, ASCE, 2000, 4, No. 2, 56-64.

2. GHOBARAH A. and SAID A. Seismic rehabilitation of beamcolumn joints using FRP laminates. Journal of Earthquake Engineering, 2001, 5, No. 1, 113-129.

3. Antonopoulous C. P. and Triantafillou T. C. Experimental investigation of FRP-strengthened RC beam-column joints. Journal of Composites for Construction, ASCE, 2003, 7, No. 1, 39-49.

4. Al-Salloum Y. A. and Almusallam T. H. Seismic response of interior RC beam-column joints upgraded with FRP sheets. I: experimental study. Journal of Composites for Construction, ASCE, 2007, 11, No. 6, 575-589.

5. Granata P. J. and PARVin A. An experimental study on Kevlar strengthening of beam-column connections. Composite Structures, 2001, 53, No. 2, 163-171.

6. GHobarah A. and El-Amoury T. Seismic rehabilitation of deficient exterior concrete frame joints. Journal of Composites for Construction, ASCE, 2005, 9, No. 5, 408-416.

7. El-Amoury T. and GHOBARAH A. Seismic rehabilitation of beam-column joint using GFRP sheets. Engineering Structures, 2002, 24, No. 11, 1397-1407.

8. MUKHERJEE A. and JoshI M. FRPC reinforced concrete beam-column joints under cyclic excitation. Composite Structures, 2004, 70, 185-199.

9. Mahini S. S., Ronagh H. R. and SMith S. T. CFRP-retrofitted RC exterior beam-column connections under cyclic loads. Proceedings of the Second International Conference on FRP Composites in Civil Engineering, CICE 2004, Adelaide, 647-652.

10. SMIth S. T. and SHRESTHA R. A review of FRP-strengthened
RC beam-column connections. Proceedings of the Third International Conference on FRP Composites in Civil Engineering, CICE 2006, Miami, 661-664.

11. Engindeniz M., KAHN L. F. and ZUREICK A. H. Repair and strengthening of reinforced concrete beam-column joints: state of the art. ACI Structural Journal, 2005, 102, No. 2, $1-14$.

12. AMERICAN CONCRETE INSTITUTE. ACI 440-2R-08: Guide for the Design and Construction of Externally Bonded FRP Systems for Strengthening Concrete Structures. ACI, Farmington Hills, Michigan, USA, 2008. ACI Committee 440.

13. StANDARDS AuSTRALIA. AS 1012. Methods of Testing Concrete. Standards Australia, Sydney, Australia.

14. American SOCIETY FOR TeSting AND Materials. ASTM ES-04. Standard Test Methods for Tension Testing of Metallic Materials. ASTM, Pennsylvania, USA, 2004.

15. American SOCiety For Testing And Materials. ASTM 3039/ D3039M. Standard Test Method for Tensile Properties of Polymer Matrix Composites Materials. ASTM, Pennsylvania, USA, 2000.

16. SHRESTHA R. Behaviour of RC Beam-Column Connections Retrofitted with FRP Strips. DPhil. dissertation, University of Technology Sydney, Australia, 2009. Under review.

17. Chen J. F. and Teng J. G. Anchorage strength models for FRP and steel plates bonded to concrete. Journal of Structural Engineering, ASCE, 2001, 125, No. 7, 784-791.

18. Chen J. F. and Teng J. G. Shear capacity of FRPstrengthened RC beams: FRP rupture. Journal of Structural Engineering, ASCE, 2003, 129, No. 5, 615-625.

19. WANG L. M. and WU Y. F. Effect of corner radius on the performance of CFRP-confined square concrete columns: test. Engineering Structures, 2008, 30, No. 2, 493-505.

20. Paulay T. and Priestley M. J. N. Seismic Design of Reinforced Concrete and Masonry Buildings. Wiley, New York, 1992.

21. CHEN J. F. and TENG J. G. Shear capacity of FRPstrengthened RC beams: FRP debonding. Construction and Building Materials, ASCE, 2003, 17, No. 1, 27-41.

22. Teng J. G., Smith S. T., Yao J. and Chen J. F. Intermediate crack induced debonding in RC beams and slabs. Construction and Building Materials, 2003, 17, No. 6-7, 447-462.

\footnotetext{
What do you think?

To comment on this paper, please email up to 500 words to the editor at journals@ice.org.uk

Proceedings journals rely entirely on contributions sent in by civil engineers and related professionals, academics and students. Papers should be 2000-5000 words long, with adequate illustrations and references. Please visit www.thomastelford.com/journals for author guidelines and further details.
} 